\title{
Arthroscopic Dorsal Capsuloplasty in Scapholunate Tears EWAS 3: Preliminary Results after a Minimum Follow-up of 1 Year
}

\author{
Benjamin Degeorge, $\mathrm{MD}^{1}$ Rémy Coulomb, MD, MSc ${ }^{1}$ Pascal Kouyoumdjian, MD, $\mathrm{PhD}^{1}$ \\ Olivier Mares, $\mathrm{MD}^{1}$ \\ ${ }^{1}$ Département de Chirurgie Orthopédique et Traumatologique, \\ Chirurgie du Rachis, CHU Carémeau, Nîmes, France \\ Address for correspondence Benjamin Degeorge, MD, Département \\ de Chirurgie Orthopédique et Traumatologique, Chirurgie du Rachis, \\ J Wrist Surg 2018;7:324-330. \\ CHU Carémeau, Place du Pr. Robert Debré, 30029 Nîmes, France \\ (e-mail: degeorge.benjamin@gmail.com).
}

\begin{abstract}
Keywords

- scapholunate ligament

- dorsal capsuloplasty

- dorsal

- capsulodesis

- wrist arthroscopy

Purpose We retrospectively evaluated the results of all arthroscopic dorsal scapholunate (SL) capsuloplasty without pinning in patients presenting predynamic instability and dorsal capsuloscapholunate septum lesions on arthro-computed tomography scan after failed medical treatment.

Materials and Methods Fifteen patients, mean age 34.3 years, underwent all arthroscopically assisted dorsal capsuloplasty. Patients were assessed preoperatively and postoperatively by a clinical (pain, Watson's test, range of motion, and strength), functional (quick disabilities of the arm, shoulder, and hand), patient-rated wrist evaluation, and Mayo wrist score scores), and radiological (SL gap and dorsal intercalated segmental instability [DISI]) examination. SL tears were evaluated during surgery by European Wrist Arthroscopy Society (EWAS) classification.

Results The mean follow-up period was 20.2 months (range, 12-41). Preoperatively, positive Watson's test was noted in all cases. DISI deformity was noted in three cases without any SL gap. The SL instability was graded EWAS IIIB $(n=8)$ or EWAS IIIC $(n=7)$. Postoperatively, positive Watson's test was noted in only one case. Activity pain decreased from 7.8 preoperatively to 2.4 postoperatively. Range of motion in flexion-extension increased from 92.9 degrees preoperatively to 126.2 degrees postoperatively. Grip strength increased from 24.2 preoperatively to 38.2 postoperatively. At final follow-up, range of motion in flexion-extension and grip strength were estimated at 87 and $91 \%$ compared with contralateral side, respectively. All functional scores were significantly improved at the last follow-up. No radiographic SL gapping in grip views or DISI deformity was noted.

Discussion Cadaveric studies demonstrated that the dorsal portion of SL ligament is critical for the stability of the SL complex. The entire arthroscopic SL capsuloplasty technique provides reliable results for pain relief, avoiding postoperative stiffness associated with open procedures. It is an alternative technique for patients with predynamic SL instability after failure of medical management and shall not prelude the resort to any further open procedure.

Level of Evidence This is a level IV, case series.
\end{abstract}

received

August 27, 2017

accepted

April 23, 2018

published online

June 8,2018
Copyright $\odot 2018$ by Thieme Medical

Publishers, Inc., 333 Seventh Avenue, New York, NY 10001, USA

Tel: +1(212) 584-4662.
DOI https://doi.org/ 10.1055/s-0038-1660446. ISSN 2163-3916. 
Lesions of the scapholunate (SL) complex are the most common causes of intracarpal instability. ${ }^{1}$ They induce rotational instability of the scaphoid and a dorsal intercalated segmental instability (DISI) of the lunate, eventually leading to SL advance collapse arthritis. ${ }^{2,3}$

The dynamic stability of the SL complex is ensured mainly by the SL interosseous ligament (SLIL) along with extrinsic stabilizers. ${ }^{4-6}$ Recent cadaveric studies have demonstrated the mechanical importance of the dorsal portion of SLIL and the dorsal capsuloscapholunate septum (DCSS), connecting the SLIL to the dorsal capsule. ${ }^{7-9}$

Arthroscopic dorsal SL capsuloplasty ${ }^{10}$ is a new, miniinvasive technique allowing the stabilization of the SL complex and pain relief in lower grade SL lesions. ${ }^{10-13}$

The main objective of this study was to analyze preliminary results of SL dorsal capsuloplasty under arthroscopic control $^{10}$ in cases of predynamic instabilities ${ }^{14}$ in patients with painful SL projection resistant to medical treatment after a minimum follow-up of 1 year.

\section{Materials and Methods}

\section{Study Outline}

Fifteen patients ( 9 men and 6 women), operated by a single trained senior operator between December 2013 and October 2015 for arthroscopic dorsal SL capsuloplasty, were reviewed.

Patients mean age was 34.3 years (range, 19-51). All patients had a wrist trauma during the months prior to the surgical intervention. The repartition of traumas was as follows: sport accident in nine cases (60\%), road traffic accident in three cases (20\%), and accident at work in three cases (20\%). The average time between trauma and surgery was 9 months (2-20). Dominant side was involved in 11 patients (73\%).
Inclusion criteria were patients with wrist pain related to a predynamic instability ${ }^{14}$ and after a failed medical treatment. All patients showed lesion of the DCSS with remnants of SL ligament on both the dorsal horn of lunate and scaphoid on the arthro-computed tomography scan. All patients had received a primary medical treatment, which consisted in wrist-splint immobilization for 21 days following a hydrocortisone intraarticular injection. All patients still experienced symptoms after this procedure. Exclusion criteria were represented by associated triangular fibrocartilage complex lesions or the presence of radio or intracarpal arthrosis. Patients with a history of wrist fracture were also excluded from the study. All patients were received in consultation by an independent examiner.

\section{Operative Technique}

The operations were realized in ambulatory surgery under local regional anesthesia with an upper arm tourniquet. An arthroscopic tower allowed vertical traction (4-5 kg) on the hand using Chinese finger traps. We used standard arthroscopic portals $3 / 4$ and $6 R$ for the radiocarpal joint and midcarpal radial site (MCR) and midcarpal ulnar site (MCU) for the midcarpal joint. A primary arthroscopic exploration and testing was performed. SL lesions were subsequently classified following European Wrist Arthroscopy Society (EWAS) (- Table 1). ${ }^{9}$ Using a motorized knife, synovectomy was performed for debriding the SL interval.

Dorsal SL capsuloplasty was then performed following the technique described by Mathoulin et al (2011). ${ }^{10}$ Two needles were inserted through the scaphoid and lunate remnants of the SLIL from radiocarpal (portal 3/4) to midcarpal (portal MCR), with a visual control on 6R portal. The key point of the technique is to insert the needles through the dorsal capsule, $1 \mathrm{~mm}$ distal from the capsule hole and not directly

Table 1 Arthroscopic EWAS classification and corresponding AP findings in cadaver specimens ${ }^{9}$

\begin{tabular}{|c|c|c|}
\hline $\begin{array}{l}\text { Arthroscopic } \\
\text { stage (EWAS) }\end{array}$ & Arthroscopic testing of SLIOL from MC joint & AP findings \\
\hline I & No passage of the probe & \\
\hline $\begin{array}{l}\text { II: lesion of } \\
\text { membranous SLIOL }\end{array}$ & $\begin{array}{l}\text { Passage of the tip of the probe in the SL } \\
\text { space without widening (stable) }\end{array}$ & Lesion of proximal/membranous part of SLIOL \\
\hline $\begin{array}{l}\text { IIIA: partial lesion } \\
\text { involving the volar SLIOL }\end{array}$ & $\begin{array}{l}\text { Volar widening on dynamic testing from } \\
\text { MC joint (anterior laxity) }\end{array}$ & $\begin{array}{l}\text { Lesion of anterior and proximal part of SLIOL } \\
\text { with or without lesion of RSC-LRL }\end{array}$ \\
\hline $\begin{array}{l}\text { IIIB: partial lesion } \\
\text { involving the dorsal SLIOL }\end{array}$ & $\begin{array}{l}\text { Dorsal SL widening on dynamic testing } \\
\text { (posterior laxity) }\end{array}$ & $\begin{array}{l}\text { Lesion of proximal and posterior part of } \\
\text { SLIOL with partial lesion of DIC }\end{array}$ \\
\hline $\begin{array}{l}\text { IIIC: complete SLIOL tear, } \\
\text { joint is reducible }\end{array}$ & $\begin{array}{l}\text { Complete widening of SL space on dynamic } \\
\text { testing, reducible with removal of probe }\end{array}$ & $\begin{array}{l}\text { Complete lesion of SLIOL (anterior, proximal, } \\
\text { and posterior), complete lesion of one } \\
\text { extrinsic ligament (DIC lesion or RSC/LRL) }\end{array}$ \\
\hline $\begin{array}{l}\text { IV: complete SLIOL } \\
\text { with SL gap }\end{array}$ & $\begin{array}{l}\text { SL gap with passage of the arthroscope from } \\
\text { MC to RC joint. No radiographics abnormalities }\end{array}$ & $\begin{array}{l}\text { Complete lesion of SLIOL (anterior, proximal, } \\
\text { and posterior), lesion of extrinsic ligaments } \\
\text { (DIC and RSC/LRL) }\end{array}$ \\
\hline $\mathrm{V}$ & $\begin{array}{l}\text { Wide SL gap with passage of the arthroscope } \\
\text { through SL joint. Frequent X ray abnormalities } \\
\text { such as increased SL gap, DISI deformity }\end{array}$ & $\begin{array}{l}\text { Complete lesion of SLIOL, DIC, LRL, RSC, } \\
\text { involvement of one or more ligament } \\
(\mathrm{TH}, \mathrm{ST} \text {, and DRC) }\end{array}$ \\
\hline
\end{tabular}

Abbreviations: AP, anatomopathological; DIC, dorsal intercarpal ligament; DISI, dorsal intercalated segmental instability; DRC, dorsoradiocarpal; EWAS, European Wrist Arthroscopy Society; MC, midcarpal; RC, radiocarpal; RCS, radioscaphocapitate; RLR, long radiolunate; SL, scapholunate; SLIOL, scapholunate interosseous ligament; ST, scaphotrapezial; TH, triquetrohamate. 
into the open part of the capsule. Two PDS $3 / 0$ suture threads were introduced in the needles and pulled out through the MCR portal using forceps. The two suture threads were then knotted together. The knot was reintroduced into the midcarpal joint through the MCR portal under visual control from MCU portal. After releasing the traction, a second knot is then tied between the two proximal suture threads into the $3 / 4$ portal performing the capsuloligamentous suture. A final arthroscopic control was performed to test the SL interval in the midcarpal joint. No SL or scaphocapitate pinning was performed.

\section{Postoperative Protocol}

A strict immobilization of the wrist using removable splint was prescribed for 21 days. Soft physiotherapy aimed at muscular reinforcement insisting on radial muscles, insisting on the flexor carpi radialis (FCR) and extensor carpi radialis longus (ECRL), ${ }^{15,16}$ was performed after the immobilization phase. Return to sports was authorized 3 months after surgery.

\section{Clinical Assessment}

Pre- and postoperative data were collected. Rest and activity pain were evaluated by the visual analog scale (VAS). Subjective and objective SL shifts using Waston's test ${ }^{17}$ were searched. Range of motion (in degrees) for wrist flexion, extension, radial, and ulnar deviation was measured. Grip strength (in $\mathrm{kg} / \mathrm{F}$ ) using a Jamar hand dynamometer (Kit Baseline, Arex, Palaiseau, France) was measured.

Evaluation of functional outcomes was undertaken with the patient-rated wrist evaluation) ${ }^{18}$ quick disabilities of the arm, shoulder, and hand), ${ }^{19}$ and Mayo wrist score ${ }^{20}$ standardized questionnaires.

At last follow-up, patients were asked to evaluate their general satisfaction regarding the surgical procedure by a five-level scale: "unsatisfied," "somewhat satisfied," "moderately satisfied," "satisfied," and "very satisfied."

\section{Radiographic Assessment}

Anteroposterior and strict lateral X-rays of the wrist and clenched fist ${ }^{21}$ were performed pre- and postoperatively to detect a SL gap over $3 \mathrm{~mm}^{22}$ and a DISI of the lunate, defined as an SL angle superior or equal to 70 degrees. ${ }^{23}$

\section{Statistical Analysis}

Statistical evaluations were performed using the SPSS software (IBM, Armonk, North Castle, NY). We applied Student's ttest for data of paired group to compare continuous variables, and Fisher's exact test for comparison of nominal variables. Statistical significance threshold was set at $p<0.05$.

\section{Results}

\section{Preoperative Arthroscopic Staging}

On dynamic testing, dorsal SL widening was described in eight patients (53\%) and complete SL widening was described in seven patients (47\%). According to EWAS staging system, eight patients were classified at stage IIIB and seven at stage IIIC ( - Table $\mathbf{1}$ ).
Table 2 Mean preoperative and postoperative scores for pain, range of motion, grip strength, and scapholunar angle with range and significance level $(p)$

\begin{tabular}{|c|c|c|c|c|}
\hline & & $\begin{array}{l}\text { Preoperative } \\
\text { scores }\end{array}$ & $\begin{array}{l}\text { Postoperative } \\
\text { scores }\end{array}$ & $p$-Value \\
\hline \multirow[t]{2}{*}{ Pain } & $\begin{array}{l}\text { Rest } \\
\text { pain }\end{array}$ & $\begin{array}{l}5.8 \\
(2-8)\end{array}$ & $\begin{array}{l}0.9 \\
(0-5)\end{array}$ & $<0.001$ \\
\hline & $\begin{array}{l}\text { Activity } \\
\text { pain }\end{array}$ & $\begin{array}{l}7.8 \\
(5-10)\end{array}$ & $\begin{array}{l}2.4 \\
(0-6)\end{array}$ & $<0.001$ \\
\hline \multirow{4}{*}{$\begin{array}{l}\text { Range of } \\
\text { motion } \\
\text { (deg) }\end{array}$} & Flexion & $\begin{array}{l}47.5 \\
(30-60)\end{array}$ & $\begin{array}{l}62.9 \\
(4-75)\end{array}$ & $<0.001$ \\
\hline & Extension & $\begin{array}{l}45.4 \\
(30-60)\end{array}$ & $\begin{array}{l}63.3 \\
(30-75)\end{array}$ & $<0.001$ \\
\hline & $\begin{array}{l}\text { Radial } \\
\text { deviation }\end{array}$ & $\begin{array}{l}18.3 \\
(5-30)\end{array}$ & $\begin{array}{l}22.9 \\
(10-30)\end{array}$ & 0.009 \\
\hline & $\begin{array}{l}\text { Ulnar } \\
\text { deviation }\end{array}$ & $\begin{array}{l}27.9 \\
(20-40)\end{array}$ & $\begin{array}{l}39.6 \\
(20-55)\end{array}$ & $<0.001$ \\
\hline \multicolumn{2}{|c|}{$\begin{array}{l}\text { Grip strength } \\
(\mathrm{kg} / \mathrm{F})\end{array}$} & $\begin{array}{l}24.2 \\
(11-36)\end{array}$ & $\begin{array}{l}38.2 \\
(21-58)\end{array}$ & $<0.001$ \\
\hline
\end{tabular}

\section{Clinical Evaluation}

The mean follow-up was 20.2 months (range, 12-41). Preoperatively, all patients presented a painful SL shift and a positive Watson's test. At follow-up, one patient presented a painless SL shift with a positive Watson's test (6.7\%) $(p<0.001)(-$ Table 2).

Pain was significantly improved $(p<0.001)$ with a mean decrease of 4.9 (range, 2-8) and 5.3 (range, 2-9) points on VAS at rest and activity, respectively.

Postoperative mean ranges of motion were 125 degrees (range, 70-140) in flexion-extension motion, and 61 degrees (range, 30-85) in radio-ulnar deviation. Postoperative ranges of motion and grip strength were significantly improved compared with preoperative values $(p<0.001)$ (-Fig. 1). At last follow-up, ranges of motion in flexionextension and in radio-ulnar deviation were evaluated at, respectively, 87 and $89 \%$ compared with the contralateral side ( - Fig. 2). Grip strength was evaluated at $91 \%$ compared with the contralateral side.

All functional scores were significantly improved in postoperative time $(p<0.001)$ ( - Table 3). Eleven patients (73\%) were very satisfied with the surgical procedure. All patients were either satisfied or very satisfied with the surgical procedure.

\section{Radiographic Assessment}

Preoperatively, no patients presented a SL gap $>3 \mathrm{~mm}$ on clenched fist X-rays. Three patients (20\%) presented a DISI of the lunate with a mean SL angle of 55 degrees (range, 40-75). At the follow-up, neither SL gap nor DISI was noted. The mean SL angle was 49 degrees (range, 40-60) with a mean decrease of 6.6 degrees (range, $0-15)(p=0.03)$.

\section{Complications}

Two patients (13\%) developed a type 1 complex regional pain syndrome. They were treated for an accident at work. 


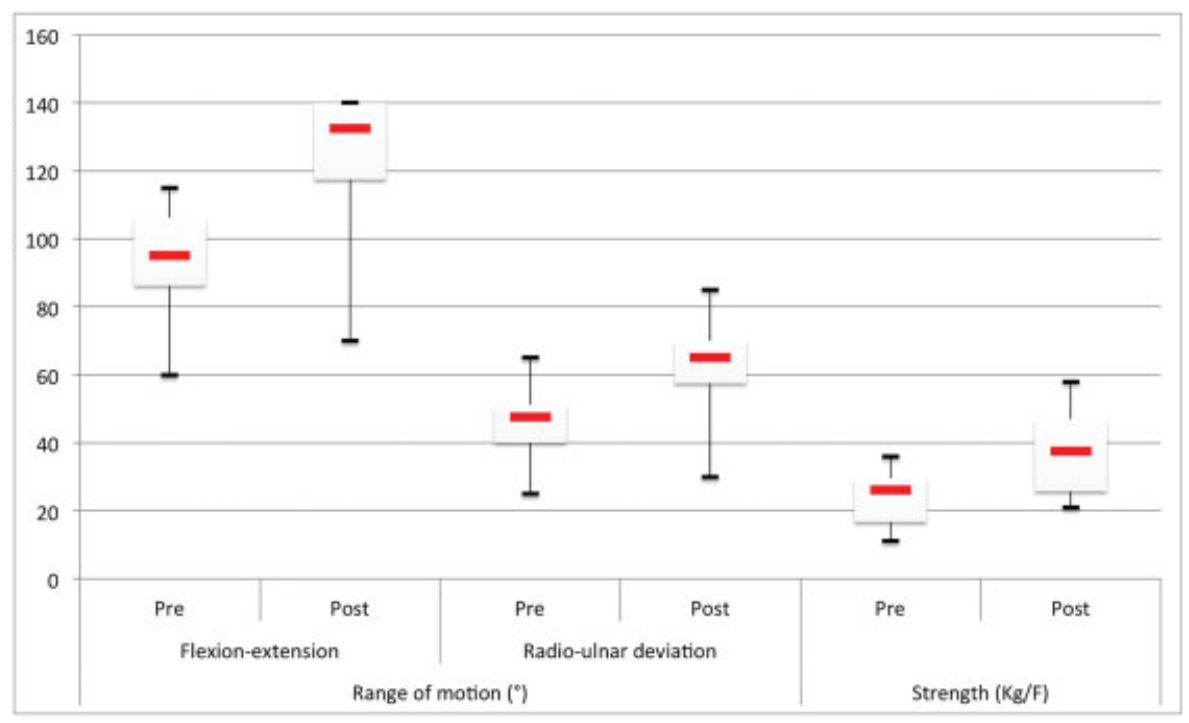

Fig. 1 Comparisons of pre- and postoperative ranges of motion and grip strength. Range of motion values correspond to the sum of active radiocarpal motion in flexion-extension and radio-ulnar deviation. All postoperative ranges of motion are significantly increased compared with preoperative data.

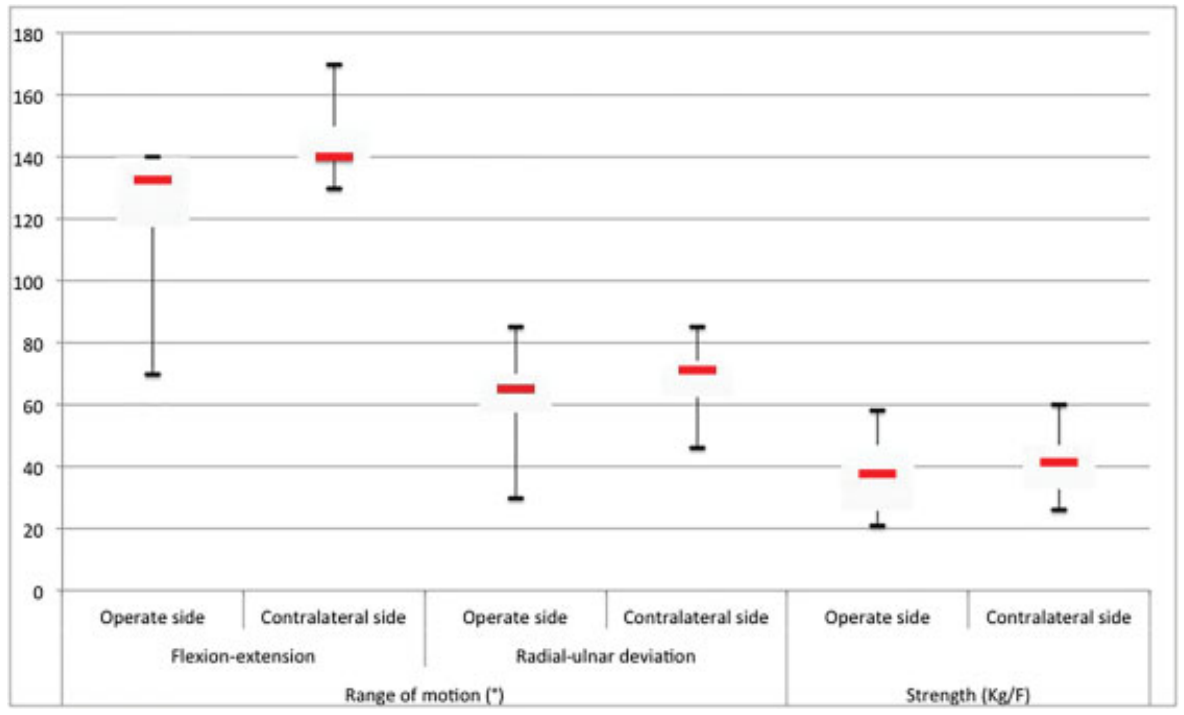

Fig. 2 Comparisons of postoperative ranges of motion and grip strength with the healthy contralateral side. Ranges of motions correspond to the sum of active radiocarpal motion in flexion-extension and radio-ulnar inclination.

\section{Discussion}

Tears of the SL complex involve changes in the normal intracarpal kinetics. ${ }^{24}$ Iterative movements of the wrist implicate acute flexion of the scaphoid with posterior rotational subluxation of its proximal pole ${ }^{25,26}$ and extension of the lunate leading to DISI under the traction of lunotriquetral fibers. ${ }^{26}$ Those iterative pathological displacements are, as demonstrated by Watson et al, ${ }^{14}$ responsible for styloscaphoid arthrosis primarily followed then by radiocarpal and intracarpal arthrosis. Thus, treatment for the initial SL tear appears essential to avoid this arthritic progression. $^{27}$

\section{Two Types of Stabilizers Compose the Scapholunate Complex}

An intrinsic stabilizer: The SLIL is composed of three portions: palmar, proximal, and dorsal. Cadaveric studies report that the dorsal portion is the most important in terms of biomechanics. ${ }^{4-6,25,28}$ Its integrity is critical and its lesion necessary $^{4-6}$ though insufficient to induce a SL instability. ${ }^{7,8,29}$ Salva-Coll et al found that proprioceptive innervation of the SLIL represents a protective factor against the degenerative process of arthrosis. ${ }^{30}$ According to the authors, proprioception resulting from this innervation would prevent excessive intracarpal mobility, hence decreasing the occurrence of cartilage degradation. 
Table 3 Mean preoperative and postoperative functional scores with range and significance level $(p)$

\begin{tabular}{|l|l|l|l|}
\hline & $\begin{array}{l}\text { Preoperative } \\
\text { scores }\end{array}$ & $\begin{array}{l}\text { Postoperative } \\
\text { scores }\end{array}$ & $p$-Value \\
\hline PRWE & $\begin{array}{l}38.2 \\
(20-65)\end{array}$ & $\begin{array}{l}11.2 \\
(0-28)\end{array}$ & $<0.001$ \\
\hline QuickDASH & $\begin{array}{l}40.5 \\
(20.4-61.4)\end{array}$ & $\begin{array}{l}15.2 \\
(0-59)\end{array}$ & $<0.001$ \\
\hline MWS & $\begin{array}{l}60.4 \\
(25-75)\end{array}$ & $\begin{array}{l}93 \\
(80-100)\end{array}$ & $<0.001$ \\
\hline
\end{tabular}

Abbreviations: MWS, Mayo wrist score; PRWE, patient-rated wrist evaluation; QuickDASH, quick disabilities of the arm, shoulder, and hand.

Three extrinsic or secondary stabilizers: ${ }^{4-6}$ The radioscaphocapitate ligament (palmar bolt), the scaphotrapeziotrapezoid ligament complex (distal bolt), and the dorsal intercarpal ligament (dorsal bolt) linked to the SL ligament by the DCSS. ${ }^{6}$

Moreover, for Salvà-Coll et al, the FCR tendon represents a dynamic stabilizer of the SL complex. ${ }^{15}$ Its action is close to the scaphotrapeziotrapezoid ligament complex and it resists the scaphoid from rotating into flexion and pronation.

In a cadaveric study, Elsaidi et $\mathrm{al}^{8}$ and Overstraeten et $\mathrm{al}^{31}$ found that the DCSS appeared to be the main stabilizer of the SL complex through its posterior capsular restraints. Mitsuyasu et al reached the same conclusions by insisting on the major role of the intercarpal dorsal ligament. ${ }^{7}$

In case of tears in the SL complex, the joint repair of DCSS and the dorsal portion of the SL ligament thus appear essential when considering its mechanical and proprioceptive functions. ${ }^{9,30}$ Specific strengthening program for the radial muscles, FCR and ECRL, is also recommended, regarding their actions on dynamic stabilization of the SL complex. ${ }^{15,16,30}$

Van Overstraeten and Camus ${ }^{32}$ and Messina et $\mathrm{al}^{9}$ consider that the genesis of SL instability would then be an association of one lesion of the interosseous SL ligament and at least one extrinsic ligament, they insist of preoperative testing of each. ${ }^{32,33}$ According to Short et al, the development of intracarpal instability following a section of the interosseous SL ligament is secondary to the deficiency of the extrinsic stabilizers. ${ }^{4-6}$

Arthroscopic dorsal SL capsuloplasty is a single, miniinvasive procedure involving few complications and providing encouraging results in terms of pain relief, mobility, and wrist strength. ${ }^{10-13}$ It also does not preclude the use of a more radical, secondary surgery. From our point of view, it is conceived only for early lesions of the SLIL without or with minimal lesions of the extrinsic stabilizers: stage 2 (even 3 ) of the Garcia-Elias et al's classification ( - Table 4$),{ }^{34}$ or stages IIIB and IIIC of the EWAS (- Table 1). ${ }^{9}$ According to GarciaElias et al, stage 2 defines a complete lesion of the SL ligament without intracarpal destabilization corresponding to the predynamic instability described by Watson et al. ${ }^{14,35}$ Stage 3 includes the dynamic intracarpal destabilization with SL gap. According to EWAS, stages IIIB and $C$ represent a subdivision of stage 2 of Garcia-Elias et al with only dorsal or complete lesion of the SLIL, respectively.

From our point of view, a single arthroscopic dorsal SL capsuloplasty appears mechanically too weak to prevent a true dynamic instability (stage 3 of Garcia-Elias et al). The aim of the procedure is to obtain a SL arthrofibrosis allowing a stabilization of the proximal pole of the scaphoid, as well as healing of the associated extrinsic ligamentous lesions. Nevertheless, Mathoulin et al highlighted a posterior capsular thickening during magnetic resonance imaging, 12 months after a dorsal arthroscopic capsuloplasty, corresponding to the scarring of the DCSS. ${ }^{10}$ Restoration of this anatomic crossroad would allow the stabilization of the SL complex in cases of more evolved instabilities (dynamic or static). According to series, indications for arthroscopic dorsal capsuloplasty were represented by gradual lesions EWAS II or III, ${ }^{12}$ or Garcia-Elias et al 2 , 3, or $4 .^{10,11,13}$ According to the original cadaveric study, these correspond to lesions of the intrinsic ligament involving a lesion of a single extrinsic stabilizer for EWAS stage IIIC. $^{9}$ Stages 3 and 4 of Garcia-Elias et al were fixed with SL and scaphocapitate pinning to maintain reduction during scarring of the procedure.

Arthroscopic dorsal SL capsuloplasty is not expected to substitute to open surgical procedures in the treatment of static SL instabilities. ${ }^{10}$ Open capsulodesis, ligamentoplasty, or partial arthrodesis is still gold standard in stages 3 to 5 of Garcia-Elias et al, corresponding to lesions EWAS IV or V and characterizing a dynamic or static SL instability. ${ }^{14}$ There are then, important associated lesions of the extrinsic stabilizers of the SL complex which are beyond, in our opinion, the arthroscopic treatment. ${ }^{9}$ Thus, comparison between the two types of open and arthroscopic procedures is not feasible because of the differences between the two treated lesions.

Several authors have studied arthroscopic dorsal SL capsuloplasty in the context of SL instability. ${ }^{10-13}$ These authors

Table 4 Staging of SLD by Garcia-Elias et al $^{34}$

\begin{tabular}{|c|c|c|c|c|c|c|}
\hline SLD stage & 1 & 2 & 3 & 4 & 5 & 6 \\
\hline Is there a partial rupture with a normal dorsal SL ligament? & Yes & No & No & No & No & No \\
\hline If ruptured, can the dorsal SL ligament be repaired? & Yes & Yes & No & No & No & No \\
\hline Is the scaphoid normally aligned (radioscaphoid angle $\leq 45 \mathrm{deg}$ )? & Yes & Yes & Yes & No & No & No \\
\hline Is the carpal malalignment easily reducible? & Yes & Yes & Yes & Yes & No & No \\
\hline Are the cartilages at both $\mathrm{RC}$ and $\mathrm{MC}$ joints normal? & Yes & Yes & Yes & Yes & Yes & No \\
\hline
\end{tabular}

Abbreviations: MD, midcarpal; RC, radiocarpal; SL, scapholunate; SLD, scapholunate dissociation. 
Table 5 Comparison of postoperative range of motion and QuickDASH scores for others authors in literature

\begin{tabular}{|c|c|c|c|c|c|c|c|}
\hline & \multirow[t]{2}{*}{ Follow-up (mo) } & \multicolumn{4}{|c|}{ Range of motion (deg) } & \multirow{2}{*}{$\begin{array}{l}\text { Grip strength } \\
(\mathrm{kg} / \mathrm{F})\end{array}$} & \multirow[t]{2}{*}{ QuickDASH } \\
\hline & & Flexion & Extension & $\begin{array}{l}\text { Radial } \\
\text { deviation }\end{array}$ & $\begin{array}{l}\text { Ulnar } \\
\text { deviation }\end{array}$ & & \\
\hline Mathoulin et $\mathrm{al}^{10}$ & 13 & $\begin{array}{l}73 \\
(40-90) \\
109 \%\end{array}$ & $\begin{array}{l}73 \\
(45-80) \\
97 \%\end{array}$ & $\begin{array}{l}27 \\
(10-30) \\
84 \%\end{array}$ & $\begin{array}{l}37 \\
(25-40) \\
96 \%\end{array}$ & $\begin{array}{l}42 \\
(30-55) \\
96 \%\end{array}$ & $\begin{array}{l}6.1 \\
(0-40.1)\end{array}$ \\
\hline Mathoulin et al $^{11}$ & 11.4 & $\begin{array}{l}63 \\
(40-80) \\
-\end{array}$ & $\begin{array}{l}71 \\
(40-90) \\
-\end{array}$ & $\begin{array}{l}24 \\
(10-40) \\
-\end{array}$ & $\begin{array}{l}34 \\
(25-40) \\
-\end{array}$ & $\begin{array}{l}39.3 \\
(20-60) \\
92 \%\end{array}$ & $\begin{array}{l}9.5 \\
(0-40.1)\end{array}$ \\
\hline Binder et al ${ }^{12}$ & 16.3 & $\begin{array}{l}65.5 \\
(45-85) \\
84 \% \\
\end{array}$ & $\begin{array}{l}74.5 \\
(70-80) \\
-\end{array}$ & $\begin{array}{l}28 \\
(15-35) \\
- \\
\end{array}$ & $\begin{array}{l}34 \\
(30-45) \\
98.6 \% \\
\end{array}$ & $\begin{array}{l}44 \\
(20-55) \\
96.6 \% \\
\end{array}$ & $\begin{array}{l}4.3 \\
(0-13.6)\end{array}$ \\
\hline $\begin{array}{l}\text { Wahegaonkar } \\
\text { and Mathoulin }{ }^{13}\end{array}$ & 30.7 & $\begin{array}{l}- \\
- \\
84.3 \%\end{array}$ & $\begin{array}{l}- \\
- \\
-\end{array}$ & $\begin{array}{l}- \\
- \\
95.7 \%\end{array}$ & $\begin{array}{l}- \\
- \\
-\end{array}$ & $\begin{array}{l}38.4 \\
(20-60) \\
93.4 \%\end{array}$ & $\begin{array}{l}8.3 \\
-\end{array}$ \\
\hline Our series & 20.2 & $\begin{array}{l}62.9 \\
(40-75) \\
86 \%\end{array}$ & $\begin{array}{l}63.3 \\
(30-75) \\
90 \%\end{array}$ & $\begin{array}{l}22.9 \\
(10-30) \\
87 \%\end{array}$ & $\begin{array}{l}39.6 \\
(20-55) \\
96 \%\end{array}$ & $\begin{array}{l}38.2 \\
(21-58) \\
91 \%\end{array}$ & $\begin{array}{l}15.2 \\
(0-59)\end{array}$ \\
\hline
\end{tabular}

Abbreviation: QuickDASH, quick disabilities of the arm, shoulder, and hand.

Note: All measures are given with mean values, range, and percentage of contralateral side.

report good to excellent results on pain relief, average range of motion. Flexion was evaluated from 84 to $100 \%$ on the contralateral side, and ulnar inclination from 96 to $99 \%$ (- Table 5). Grip strength was more than $91 \%$ on the contralateral side. We report the same findings with mean scores of 86 and 96\% for flexion and lunar deviation, respectively, compared with the contralateral side. Regarding radiographic results, Wahegaonkar and Mathoulin found correction of the lunate DISI in $87 \%$ of cases, with a mean decrease of the SL angle of 8.9 degrees in postoperative. ${ }^{13}$ Our results are similar to these findings with a reduction of the DISI in every cases. However, DISI deformity of the lunate in our study corresponded to limited cases (SL angles at 70 degrees in two cases and 75 degrees in one case). It remains possible that these three cases represented false positive despite our repeated measurements, and that no DISI was included in the study.

Zarkadas et al performed a multicentric retrospective survey in North America on open surgical management of SL instabilities including all stages of SL tears. ${ }^{36}$ In case of acute and chronic lesion, postoperative range of motion were more than $80 \%$ on the contralateral side in only 10 and $1 \%$ of cases, respectively. Similarly, they found a $75 \%$ greater strength on the contralateral side in only 44 and $18 \%$ cases, respectively. Occasional pain during moderate usage of the right wrist after surgery was, respectively, found in 80 and $84 \%$ of acute and chronic lesions.

The results of arthroscopic dorsal SL capsuloplasty are encouraging. We report, in agreement with the literature, ${ }^{10-13}$ excellent results for pain relief, wrist range of motion, and grip strength, clearly improved at revision. Nevertheless, it is essential to nuance these results. The observed clinical improvement could be due to-at least in part-the natural evolution of SL lesions described as the "honeymoon" effect by Watson et al. ${ }^{14}$ Arthroscopic debridement of the SL interval could also explain the postoperative clinical improvement induced by the resection of the inflammatory synovitis and some form of denervation of the wrist. ${ }^{37,38}$ Both series found significant clinical improvement after arthroscopic debridement alone for SL tears. ${ }^{37,38}$ However, do not repair the SLIL could induce secondary intracarpal instability by deficiency of the extrinsic stabilizers. ${ }^{4-6}$ Only a comparative study between arthroscopic dorsal capsuloplasty and arthroscopic debridement would allow to clarify the beneficial effect of capsuloplasty on pain relief and overall stability. Finally, it would be wise to evaluate the mechanical capacities of arthrofibrosis created by dorsal capsuloplasty.

No biomechanical study has been carried to demonstrate the stabilizing effect of arthroscopic dorsal SL capsuloplasty. Does DCSS suture allow for the restoration of normal carpal kinetics? The difficulty of such study lies in the fact that capsulodesis and arthrofibrosis require scarring tissues, which is impossible to achieve during cadaveric studies. Nonetheless, postoperative disappearing of SL symptoms leads us to think that dorsal SL capsuloplasty is effective.

We described two cases of complex regional pain syndrome was found in our series. Despite the psychological aspect of the accident at work, it remains possible that a lesion of the posterior interosseous nerve during the procedure could lead to a complex regional pain syndrome.

No studies include sufficient long-term postoperative checks seeking to find rotational stagger of the scaphoid as well as posterior damages of radioscaphoid cartilage, both indicators of failure of the procedure. Long-term monitoring is essential to look for these signs of instability and prevent arthrosis, by using a more radical stabilizing technique on the SL complex.

\section{Conclusion}

Arthroscopic dorsal SL capsuloplasty provides encouraging results, both clinically and functionally in cases of SL tears 
EWAS 3. It is a single, minimally invasive procedure with low rate of complications and excellent results regarding to pain relief, range of motion, and grip strength.

It must be performed in the strict context of predynamic instability mainly corresponding to SL intrinsic ligaments tears, always after failed medical treatment.

This procedure does not offer a replacement for open surgery procedures and allows for a subsequent more radical surgery, if needed.

\section{Funding}

None.

\section{Conflict of Interest}

None.

\section{References}

1 Kozin SH. The role of arthroscopy in scapholunate instability. Hand Clin 1999;15(03):435-444

2 O'Meeghan CJ, Stuart W, Mamo V, Stanley JK, Trail IA. The natural history of an untreated isolated scapholunate interosseus ligament injury. J Hand Surg [Br] 2003;28(04):307-310

3 Pomeranz SJ, Salazar P. Scapholunate advanced collapse. J Surg Orthop Adv 2015;24(02):140-143

4 Short WH, Werner FW, Green JK, Masaoka S. Biomechanical evaluation of ligamentous stabilizers of the scaphoid and lunate. J Hand Surg Am 2002;27(06):991-1002

5 Short WH, Werner FW, Green JK, Masaoka S. Biomechanical evaluation of the ligamentous stabilizers of the scaphoid and lunate: part II. J Hand Surg Am 2005;30(01):24-34

6 Short WH, Werner FW, Green JK, Sutton LG, Brutus JP. Biomechanical evaluation of the ligamentous stabilizers of the scaphoid and lunate: part III. J Hand Surg Am 2007;32(03):297-309

7 Mitsuyasu H, Patterson RM, Shah MA, Buford WL, Iwamoto Y, Viegas SF. The role of the dorsal intercarpal ligament in dynamic and static scapholunate instability. J Hand Surg Am 2004;29(02):279-288

8 Elsaidi GA, Ruch DS, Kuzma GR, Smith BP. Dorsal wrist ligament insertions stabilize the scapholunate interval: cadaver study. Clin Orthop Relat Res 2004;(425):152-157

9 Messina JC, Van Overstraeten L, Luchetti R, Fairplay T, Mathoulin CL. The EWAS classification of scapholunate tears: an anatomical arthroscopic study. J Wrist Surg 2013;2(02):105-109

10 Mathoulin C, Dauphin N, Sallen V. Arthroscopic dorsal capsuloplasty in chronic scapholunate ligament tears: a new procedure; preliminary report. Chir Main 2011;30(03):188-197

11 Mathoulin CL, Dauphin N, Wahegaonkar AL. Arthroscopic dorsal capsuloligamentous repair in chronic scapholunate ligament tears. Hand Clin 2011;27(04):563-572

12 Binder AC, Kerfant N, Wahegaonkar AL, Tandara AA, Mathoulin CL. Dorsal wrist capsular tears in association with scapholunate instability: results of an arthroscopic dorsal capsuloplasty. J Wrist Surg 2013;2(02):160-167

13 Wahegaonkar AL, Mathoulin CL. Arthroscopic dorsal capsuloligamentous repair in the treatment of chronic scapho-lunate ligament tears. J Wrist Surg 2013;2(02):141-148

14 Watson HK, Weinzweig J, Zeppieri J. The natural progression of scaphoid instability. Hand Clin 1997;13(01):39-49

15 Salvà-Coll G, Garcia-Elias M, Llusá-Pérez M, Rodríguez-Baeza A. The role of the flexor carpi radialis muscle in scapholunate instability. J Hand Surg Am 2011;36(01):31-36

16 León-López MM, García-Elías M, Salvà-Coll G, Llusá-Perez M, Lluch-Bergadà A. [Muscular control of scapholunate instability.
An experimental study]. Rev Esp Cir Ortop Traumatol 2014;58 (01):11-18

17 Watson HK, Ashmead D IV, Makhlouf MV. Examination of the scaphoid. J Hand Surg Am 1988;13(05):657-660

18 MacDermid JC, Turgeon T, Richards RS, Beadle M, Roth JH. Patient rating of wrist pain and disability: a reliable and valid measurement tool. J Orthop Trauma 1998;12(08):577-586

19 Jester A, Harth A, Wind G, Germann G, Sauerbier M. Disabilities of the arm, shoulder and hand (DASH) questionnaire: determining functional activity profiles in patients with upper extremity disorders. J Hand Surg [Br] 2005;30(01):23-28

20 Cooney WP, Bussey R, Dobyns JH, Linscheid RL. Difficult wrist fractures. Perilunate fracture-dislocations of the wrist. Clin Orthop Relat Res 1987;(214):136-147

21 Moneim MS. The tangential posteroanterior radiograph to demonstrate scapholunate dissociation. J Bone Joint Surg Am 1981;63(08):1324-1326

22 Schimmerl-Metz SM, Metz VM, Totterman SM, Mann FA, Gilula LA. Radiologic measurement of the scapholunate joint: implications of biologic variation in scapholunate joint morphology. J Hand Surg Am 1999;24(06):1237-1244

23 Gilula LA, Weeks PM. Post-traumatic ligamentous instabilities of the wrist. Radiology 1978;129(03):641-651

24 Eschweiler J, Stromps JP, Rath B, Pallua N, Radermacher K. Analysis of wrist bone motion before and after SL-ligament resection. Biomed Tech (Berl) 2016;61(03):345-357

25 Berger RA, Imeada T, Berglund L, An KN. Constraint and material properties of the subregions of the scapholunate interosseous ligament. J Hand Surg Am 1999;24(05):953-962

26 Short WH, Werner FW, Fortino MD, Palmer AK, Mann KA A dynamic biomechanical study of scapholunate ligament sectioning. J Hand Surg Am 1995;20(06):986-999

27 Kitay A, Wolfe SW. Scapholunate instability: current concepts in diagnosis and management.J Hand Surg Am 2012;37(10):2175-2196

28 Berger RA. The gross and histologic anatomy of the scapholunate interosseous ligament. J Hand Surg Am 1996;21(02):170-178

29 Viegas SF, Yamaguchi S, Boyd NL, Patterson RM. The dorsal ligaments of the wrist: anatomy, mechanical properties, and function. J Hand Surg Am 1999;24(03):456-468

30 Salva-Coll G, Garcia-Elias M, Hagert E. Scapholunate instability: proprioception and neuromuscular control. J Wrist Surg 2013;2 (02):136-140

31 Overstraeten LV, Camus EJ, Wahegaonkar A, et al. Anatomical description of the dorsal capsulo-scapholunate septum (DCSS)arthroscopic staging of scapholunate instability after DCSS sectioning. J Wrist Surg 2013;2(02):149-154

32 Van Overstraeten L, Camus EJ. The role of extrinsic ligaments in maintaining carpal stability - a prospective statistical analysis of 85 arthroscopic cases. Hand Surg Rehabil 2016;35(01):10-15

33 Van Overstraeten L, Camus EJ. A systematic method of arthroscopic testing of extrinsic carpal ligaments: implication in carpal stability. Tech Hand Up Extrem Surg 2013;17(04):202-206

34 Garcia-Elias M, Lluch AL, Stanley JK. Three-ligament tenodesis for the treatment of scapholunate dissociation: indications and surgical technique. J Hand Surg Am 2006;31(01):125-134

35 Watson HK, Ballet FL. The SLAC wrist: scapholunate advanced collapse pattern of degenerative arthritis. J Hand Surg Am 1984;9 (03):358-365

36 Zarkadas PC, Gropper PT, White NJ, Perey BH. A survey of the surgical management of acute and chronic scapholunate instability. J Hand Surg Am 2004;29(05):848-857

37 Tan SW, Ng SW, Tan SH, Teoh LC. Arthroscopic debridement of intercarpal ligament and triangular fibrocartilage complex tears. Singapore Med J 2012;53(03):188-191

38 Weiss AP, Sachar K, Glowacki KA. Arthroscopic debridement alone for intercarpal ligament tears. J Hand Surg Am 1997;22(02): 344-349 